$50 \mathrm{mg} / 100 \mathrm{ml}$

- Xơ vữa mạch máu não: Chiểm tỷ lệ 15.38\%.

2. XHDN và các tổn thương liên quan

- Tổn thương da và tổ chức dưới da chiếm tỷ lệ 95.9\%. Cụ thể bầm tụ máu dưới da đầu chiếm $85.7 \%$, xây sát da đầu gặp ở $73.5 \%$ số trường hợp, rách da đầu chiếm $44.9 \%$ và đụng dập da đầu chỉ chiếm 20.4\%. Đa số nạn nhân có võ xương sọ (75.5\%), tỷ lệ xõ võ xương sọ gấp 3 lần so với không võ.

- Trên đại thể, nhiều thương tổn kèm theo XHDN, chiếm tỷ lệ cao nhất là phù não $(77.6 \%)$, thoát vị hạnh nhẩn tiểu não $(67.3 \%)$, tiếp theo là dập não $(57.1 \%)$, MTDMC (49\%), MTNCM $(32.7 \%)$, xuất huyết nhu mô não $(40.8 \%)$ và xuất huyết não thất là thấp nhất với $16.3 \%$.

- Trên mô bệnh học, phù não vẫn chiếm đa số với $69.23 \%$, xuất huyết nhu mô não gặp ở $61.54 \%$, dập não chiếm $53.85 \%$ và cuối cùng là xuất huyết dưới nhê̂n với 46.15\%.

- Đa số là XHDN do chấn thương với 89.8\%. Tỷ lệ XHDN do bệnh lý mạch máu não chiếm 10.2\%

\section{TÀI LIÊU THAM KHẢO}

1. Punitha R, Kumar M.V, Rayamane A.P, et al. (2014). Natural Intracranial Hemorrhage and Its
Forensic Implications: A Case Review. Journal of Indian

2. Edirisinghe P.A.S (2011). Subarachnoid haemorrhage as a cause of death: a review of forensic autopsies conducted in Edinburgh. Sri Lanka Journal of Forensic Medicine, Science \& Law, 1.

3. Nikolić S, Banjanin I, Stanojević A (2004). Subarachnoidal hemorrhage from berry aneurysms as a cause of natural death. Srpski arhiv za celokupno lekarstvo, 132, 236-239.

4. Inagawa $T$, Hirano A (1990). Ruptured intracranial aneurysms: an autopsy study of 133 patients. Surgical neurology, 33, 117-123

5. Brisman J.L, Song J.K, Newell D.W (2006). Cerebral aneurysms. New England Journal of Medicine, 355, 928-939.

6. Gonsoulin M, Barnard J.J, Prahlow J.A (2002). Death resulting from ruptured cerebral artery aneurysm: 219 cases. The American journal of forensic medicine and pathology, 23, 5-14

7. Nguyễn Văn Liệu (2012). Nghiên cứu nguyên nhân chảy máu dưới nhện không do chấn thương tại khoa thân kinh bệnh viện Bach Mai trong ba năm 2009-2011. Tạp chí Y học Việt Nam, 393, 1-4.

8. Modi N.J, Agrawal M, Sinha V.D (2016). Posttraumatic subarachnoid hemorrhage: A review. Neurology India, 64, 8.

9. Shkrum M.J, Ramsay D.A (2007), Forensic pathology of trauma, Springer Science \& Business Media.

\title{
THAY 8 KHỚP BÀN NGÓN TAY BẰNG VÂTT LIỆU SILICONE NHÒ̀ CÔNG NGHỆ IN 3D CHO BẾNH NHÂN VIÊM KHỚP DANG THẤP BÀN TAY 2 BÊN. NHÂN 1 TRƯỜNG HợP
}

\author{
Trần Quyết ${ }^{1}$, Trần Trung Dũng ${ }^{1,2}$, Phạm Trung Hiếu ${ }^{1,2}$, \\ Vũ Tú Nam ${ }^{1,2}$, Phan Khoa Nguyên ${ }^{1}$

\section{TÓM TẮT} \\ Viêm khớp dạng thấp là một bệnh gặp ở mọi quốc \\ gia trên thế giới. Tỷ lệ bệnh chiếm khoảng 0,5\%-1\% \\ dân số ở châu Âu và khoảng $0,17-0,3 \%$ tại các nước \\ châu Á. Bệnh thường gặp ở nữ giới với tỳ lệ nữ/nam \\ thay đổi từ 2,5 đến 1 . Đầy là một bệnh lý tự miến điển \\ hình, diễn biến mạn tính với các biểu hiển tại khớp \\ tiến triển theo thởi gian, hay gặp nhất là các khớp \\ ngoại biên, đặc biệt là khớp bàn, ngón tay. Khi không \\ điêu trị đúng cách bệnh sẽ tiến triển nặng, có thể dẫn \\ đến những biến chứng nặng nề hoặc tàn phế ảnh \\ hưỡng đến chất lượng cuộc sông của người bệnh. \\ Phẫu thuật thành công thay 8 khớp nhân tạo bàn tay \\ ${ }^{1}$ Bệnh viện ĐK Tâm Anh \\ ${ }^{2}$ Trường Đại Hoc Y Hà Nôi \\ Chịu trách nhiệm chính: Trần Quyết \\ Email: quyettran.bs@gmail.com \\ Ngày nhận bài: 26.11.2020 \\ Ngày phản biện khoa họ: 29.12.2020 \\ Ngày duyệt bài: 8.01.2021 \\ bao gồm 7 khớp bàn ngón và 1 khớp liên đốt gân \\ ngón tay cho 1 bệnh nhân bị viêm khớp dạng thấp có \\ tổn thương nặng, biến dạng, trật khớp bàn ngón tay 2 \\ bên. Xin trình bày những vấn đề tổng quan về thay \\ khớp bàn ngón và giới thiệu ca lâm sàng.

\section{SUMMARY \\ REPLACING 8 ARTIFICIAL HAND JOINTS WITH SILICONE IMPLANTS BY 3D PRINTING TECHNOLOGY FOR PATIENT WITH RHEUMATOID ARTHRITIS IN HANDS} \\ ON BOTH SIDES. A CASE REPORT \\ Rheumatoid arthritis is a disease found in every \\ country in the world. The rate of incidence accounts \\ for about $0.5 \%-1 \%$ among Europe's population and \\ about $0.17-0.3 \%$ in Asian countries. This disease is \\ common among women with a female: male ratio \\ ranging from 2.5 to 1 . It is a typical, chronic \\ progressive autoimmune disease with progressive joint \\ manifestations over time. The disease most commonly \\ affects peripheral joints, especially the MCP and wrist
}


joints. When not properly treated, the disease will progress quickly. In most cases, it can lead to severe complications and disability as symptoms spread to wrists, knees, ankles, elbows, negatively affecting the patient's quality of life. Successful finger joint replacement surgery for a patient exhibiting severe symptoms such as deformities, dislocations of the two fingers will involve placing 8 artificial hand joints including $7 \mathrm{MCP}$ joints and 1 PIP. For the purpose of this study, we present an overview of rheumatoid arthritis and introduction of clinical case.

Keywords: Finger joint replacement surgery

\section{TỔNG QUAN VỀ KHỚP BÀN NGÓN TAY}

Đặc điểm của các khớp bàn -ngón tay (MCP) và các khớp liên đốt ngón tay (khớp liên đốt gần - PIP và khớp liên đốt xa - DIP); đây là những khớp nhỏ, dạng khớp bản lề với cử động chính là gập và duỗi, liên kết giữa xương bàn tay và các xương đốt ngón tay. Các khớp của bàn - ngón tay đóng vai trò quan trọng trong các động tác tinh tế, cầm nắm của bàn tay con người. Tham gia vào yếu tố đảm bảo độ vững cho hoạt động của các khớp này trong cả chiều trước sau, trong ngoài, ngoài hệ thống bao khớp và hệ thống gân gấp, gân duỗi ngón, còn có hệ thống dây chẳng bên của các khớp liên đốt ngón. Các khớp bàn ngón, liên đốt - ngón chủ yếu thường bị hư hỏng do các nguyên nhân như thoái hóa khớp, chấn thương cũ gây hư hỏng hoặc mất chức năng khớp, viêm khớp dạng thấp gây biến dạng và mất chức năng khớp...

Đối với những trường hợp điều trị nội khoa không cải thiện hoặc tổn thương giai đoạn cuối gây phá hỏng hoàn toàn bề mặt khớp, khớp mất chức năng thì trước đây phương pháp điêuu trị chủ yếu là đóng cứng khớp vĩnh viển để giải quyết tình trang đau của bệnh nhân, nhưng đồng thời làm mất luôn chức năng vân đô̂ng của khớp.

Ngày nay Để giải quyết những vấn đề trên của các bệnh nhân có bệnh lý thoái hóa, hỏng khớp bàn-ngón, liên đốt ngón nhưng vẫn muốn đảm bảo khả năng phục hồi chức năng của bàn ngón tay, phương pháp thay khớp đã được đề ra. Có 2 loại khớp bàn - ngón nhân tạo phổ biến được sử dụng là khớp một khối (liển khối) và khớp 2 khối, đặc điểm chung của cả 2 loại khớp là dựa trên nguyên lý bản lề và thiết kế theo đặc điểm giải phẩu của bàn ngón tay, do đó không chỉ giúp bệnh nhân giảm đau mà còn khôi phục tối đa chức năng của các khớp này.

\section{CA LÂM SÀNG}

Bệnh nhân nữ 33 tuổi đã phát hiện viêm khớp dạng thấp 20 năm, tự điều trị khồng theo liệu trình, vào viện trong tình trạng khớp bàn ngón tay 2 bên đau nhiều, biến dạng kèm trật khớp bàn ngón tay 2,3,4,5 bên trái, biến dạng kèm trật khớp bàn ngón 2,3,4 và khớp liên đốt gần ngón 5 tay phải. Bàn tay biến dạng kiểu "gió thổi" khiến bệnh nhân vận động rất khó khăn và không thể tự cầm nắm chủ động bàn tay, không thực hiện được động tác đối chiếu các ngón, không thể dạng khép các ngón tay. Bệnh nhân được tiến hành thay khớp bàn ngón 2,3,4,5 tay trái, thay khớp bàn ngón 2,3,4 tay phải và thay khớp liên đốt gần ngón 5 tay phải bằng vật liệu silicone với công nghệ in 3D tại Việt Nam.

Về đường mổ chúng tôi dự kiến 2 đường mổ, có thể sử dụng đường mổ dọc mặt mu ngón tay hoặc 1 đường ngang đi qua cả 4 khớp bàn ngón. Bàn tay phải vẹo trục nặng hơn, trật khớp bàn ngón $2,3,4$, biển dạng ngón 5 . chúng tôi tiến hành mố bàn tay phải trước và phải tính toán đến phương án phải chuyển gân cơ giun để chỉnh trục ngón nên chúng tôi đi đường dọc mặt mu tay của khớp bàn ngón 2,3,4 để bộc lộ khớp, đồng thời thực hiện thay khớp liên đốt gần ngón 5 bằng đường mổ mu ngón tay. Tuy nhiên trong quá trình thao tác, việc tạo hình da và cân bằng phần mềm bao khớp đủ để làm cải thiên trục ngón mà không cần chuyển gân cơ giun nển đường mổ bàn tay trái chúng tôi dùng 1 đường ngang mặt mu tay qua toàn bộ khớp bàn ngón để bộc lộ cả 4 khớp, tránh được nhiều sẹo mổ. Sau khi bộc lộ khớp dùng cưa chuyên dụng cắt bỏ phần sụn hỏng. Roa ống tủy 2 đầu xương theo các cỡ. Đặt các khớp thử và test vận động. Đặt khớp nhân tạo và khâu phục hồi phần mềm. Sau mổ bệnh nhân được cố định toàn bộ ngón tay phẫu thuật với nẹp chuyên dụng trong ngày đầu sau mố. Ngày thứ 2 sau mổ chúng tôi cho bệnh nhân tập thụ động ngón và ngày thứ 3 bệnh nhân có thể tập chủ động cổ tay và ngón tay. Sau khoảng 1 tuần bệnh nhân hết đau và có thể chủ động đối chiếu được các ngón và nắm duỗi bàn tay dễ dàng.

Dưới đây là hình ảnh bàn tay trước mổ và sau mổ của bệnh nhân

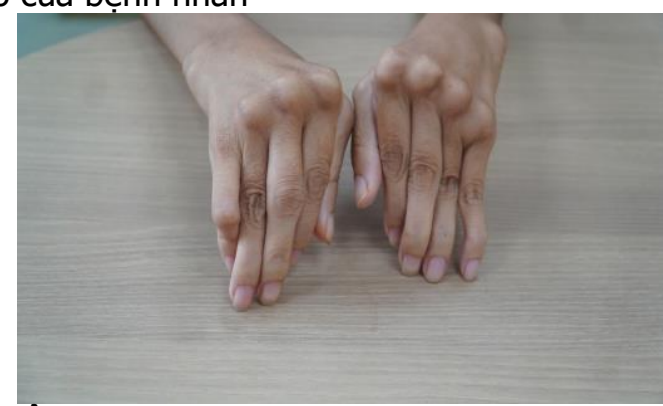

Ảnh 1: Bàn tay trước mổ của bệnh nhân, bàn tay gió thổi, lệch trục, trật nhiều khớp 


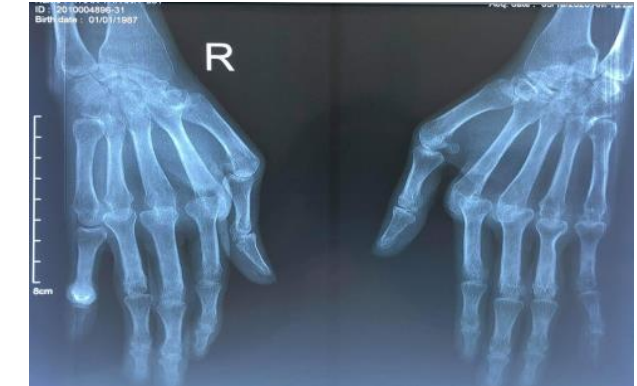

Ảnh 2: Xquang trước mổ của bệnh nhân

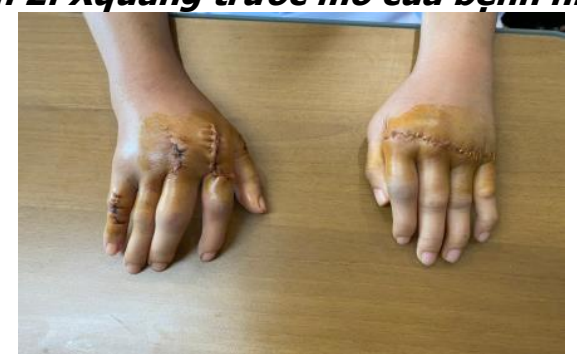

Ảnh 3: Bàn tay ngay sau mổ của bệnh nhân

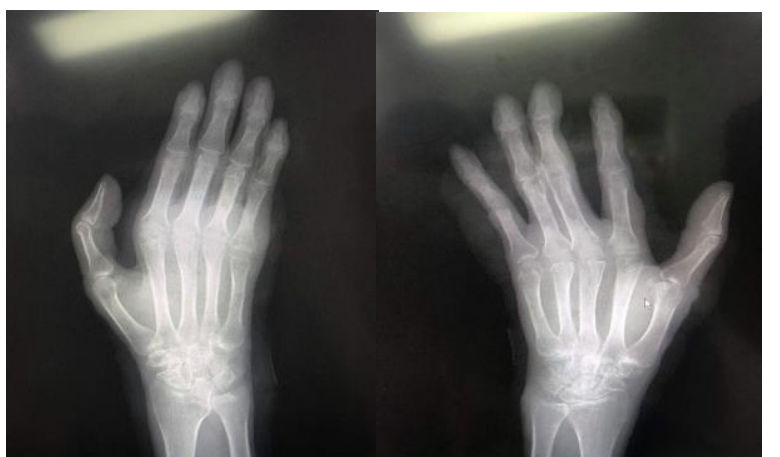

Ánh 4: Xquang sau mổ bàn tay trái

\section{BÀN LUẬN}

Đặc điểm tổn thương các khớp của Viêm khớp dạng thấp: tổn thương sớm nhất thường là khớp liển đốt gần và khớp bàn ngón tay và khớp cổ tay. Trong thời gian 2 năm đầu của bệnh, thì hơn $10 \%$ bềnh nhân viêm khớp dạng thấp sẽ phát triển biến dạng ở các khớp nhỏ bàn tay, bao gồm khớp liên đốt gần và khớp bàn ngón. Ít nhất 1 phần 3 trong số đó sẽ biến dạng nặng hơn theo thời gian, dẫn tới hậu quả đau và mất chức năng bàn ngón tay.

Khi đó phẫu thuật được đặt ra với 2 mục tiêu: giảm đau và phục hồi vận động của bàn tay. Trong đó đóng cứng khớp chỉ đáp ứng được mục tiêu giảm đau mà không khôi phục được chức năng của bàn ngón tay. Cùng với sự phát triển của kỹ thuật thay khớp, phương pháp thay khớp nhân tạo bàn ngón tay ra đời giúp bệnh nhân giải quyết được 2 vấn đề trên.
Có rất nhiều chất liệu để tạo nên loại khớp bàn ngón như: chất liệu silicone, chất liệu bằng hợp kim $\mathrm{CoCr}$ và ti tan hay khớp được làm bằng chất liệu polyethylene.

Tương ứng với đó sẽ có 3 loại khớp nhân tạo bàn ngón mà bệnh nhân có thể lựa chọn, trong đó mỗi loại có những ưu nhược điểm riêng.

- Khớp silicone do Swanson sử dung lần đầu tiên vào năm 1964 để thay cho khớp bàn ngón và 1 năm sau đó ông dùng chính vật liệu này để thay cho khớp liên đốt ngón gần. Đặc điểm của khớp silicone là loại 1 khối, hoạt động theo nguyên lý piston gẳn đẩy vào ống tủy, không cần cắt nhiều xương hay dùng xi măng, phân bổ lực của khớp đều và tính thích ứng với xương của khớp ổn định đã đem lai nhiều ưu điểm và sự hài lòng. Tuy nhiên đối với khớp liên đốt ngón tay, vì đặc điểm cấu tạo của khớp có tầm vận động và cường độ hoạt động cao hơn, cũng như cần sự đảm bảo vững của 2 phía dây chằng bên nên khớp liền khối silicone chưa thực sự thỏa măn được nhu cầu của bệnh nhân, ngoài ra ở 1 số ít trường hợp các mảnh silicone bong ra có thể gây ra triệu chứng viêm màng hoạt dịch.

- Khớp nhân tạo bằng polyethylene được Linscheid đề xuất vào năm 1997. Đây là loại khớp 2 khối: Khớp này có ưu điểm là cắt ít xương, độ vững của khớp khá cao nên thường áp dụng cho những người trẻ tuổi hoặc trung niên bị thoái hóa khớp sau chấn thương với mức độ vận động nhiều. Mặc dù vậy vẫn có nhược điểm cho loại khớp này đó là nguy cơ võ̃ xương hoặc đặt lệch implant so với trục của xương, thểm nữa khi làm khớp này thì vẩn đề cân bằng gân và phần mềm phải cực kỳ chuẩn xác để tránh nguy cơ trật khớp.

- Khớp bàn ngón tay nhân tạo bằng Pyrocarbon được tác giả Stanley người Anh công bố và đưa vào sử dụng vào năm 2001. Cũng là loai khớp 2 khối dang bản lề với chất liêu làm bẳng pyrocarbon cùng lõi graphite, chuôi khớp được gắn vào ống tủy bằng xi măng hoăcc không xi măng. Thiết kế này đã giúp giải quyết những khuyêt điểm của khớp silicone, đảm bảo độ vững chắc của chuôi khớp trên cả 4 chiều không gian, khớp này có độ bào mòn thấp nên thời gian sứ dụng khớp được khá dài, khoảng 20-25 năm. Tuy nhiên khớp này phải cắt nhiều xương hơn, chi phí cuộc mổ lớn hơn cũng như yêu cầu trình độ của phẫu thuật viên cao hơn nên khớp này ưu tiên sử dụng ở những quốc gia phát triển và ít phổ biến ở Việt Nam.

Hai loại khớp polyethylen và pyrocarbon hiện tại ở Việt Nam chưa tự sản xuất, vật liệu khớp 
vẫn phải nhập ngoại nên chi phí khá cao. Hơn nữa đòi hỏi trình độ cao của phẫu thuật viên nên loại khớp hai khối bằng hai vật liệu trển sử dụng ở các nước phát triển, ít áp dụng ở Việt Nam. Khớp làm bằng vật liệu silicone liền khối hiện tại sản xuất được ở Việt Nam với công nghệ in 3D, chi phí khá rẻ và phương pháp phẫu thuật không quá phức tạp. Hơn nữa sau phẫu thuật bệnh nhân vận động sớm ngay sau mổ, hiệu quả của phẫu thuật gần như tức thì nên thường được ưu tiên sử dụng tại Việt Nam.

Trên thế giới cũng nhiều tác giả thực hiên thay khớp bàn ngón tay bằng silicone và cho kết quả rất khả quan với thời gian theo dõi sau mổ khác nhau: Năm 2018 Tác giả Nathan T morrell và Arnoid peter Weiss công bố thực hiện thay khớp bàn ngón cho 35 bệnh nhân và theo dõi trong 15 năm cho kết quả tốt về lâm sàng 97\% và Xquang là $88 \%$.

Năm 2014 tác giả Bales, Wall và Stern công bố đã tiến hành thay khớp bàn ngón cho 51 bệnh nhân sử dụng khớp silicone theo dõi trong 10 năm thì tỷ lệ tồn tại của khớp silicone là $90 \%$ và bệnh nhân hài lòng với kết quả.

Rettig và Luca báo cáo 12 trong số 13 trường hợp thay khớp bằng silicone đạt hiệu quả tốt đến xuất sắc về khả năng vận động trên tất cả số bệnh nhân với khoảng theo dõi 40 tháng. Khả nằng gấp ngón được cải thiện đáng kể.

\section{KẾT LUÂN}

Với nhiều ưu điểm như phẫu thuật đơn giản, chi phí khá rẻ so với các vật liệu khác, thời gian phục hồi nhanh, hiệu quả giảm đau và phục hồi chức năng sau mổ gân như tức thì. Phương pháp thay khớp bàn ngón tay bằng vật liệu silicone là một lựa chọn rất tốt đối với bệnh nhân chấn thương hoặc bệnh lý như viêm khớp dạng thấp gây mất chức năng khớp bàn ngón hoặc khớp liên đốt ngón tay trong điêu kiện Việt Nam.

\section{TÀI LIÊU THAM KHẢO}

1. J Hand Surg Am. 2018 Mar; 43(3):229-233. doi: 10.1016/j.jhsa.2017.10.010. Epub 2017 Nov 14.

2. J Hand Surg Am. 2014 Mar; 39(3):455-61. doi: 10.1016/j.jhsa.2013.11.008.

3. Acta Orthop Belg. 2014 Jun;80(2):190-5.

4. Hand Clin. 2018 May; 34(2):195-205. doi: 10.1016/j.hcl.2017.12.009. Review.

5. Swanson AB. Silicone rubber implants for replacement of arthritis or destroyed joints in the hand. Surg Clin North Am. 1968; 48:1113-1127.

6. Swanson AB, Maupin BK, Gajjar NV, De Groot Swanson G. Flexible implant arthroplasty in the proximal interphalangeal joint of the hand. J Hand Surg Am. 1985(10):796-805.

7. Orthopade. 2019 May:48(5):378-385. doi: 10.1007/s00132-019-03705-w. Review. German.

8. J Hand Surg Am. 2018 Jun;43(6):574. e1574.e9. doi: 10.1016/j.jhsa.2018.03.008. Epub 2018 Apr 9. Review.

9. J Hand Surg Am. 2014 Jun;39(6):1075-81. doi: 10.1016/j.jhsa.2014.03.033. Epub 2014 May 5.

\section{MộT SỐ YẾU Tố Có LIÊN QUAN ĐẾN KẾT QUẢ PHỤC HồI CHỨC NĂNG BẰNG PHƯƠNG PHÁP GƯO'NG TRI LIẾU KẾT HợP VỚI VÂ̂N ĐộNG TRI LIỆU Ở BÊ̂NH NHÂN LIỆT NỬA NGƯỜI DO ĐộT QUỴ NÃO}

\section{Vũ Thị Tâm ${ }^{1}$, Nguyễn Phương Sinh ${ }^{1}$, Nguyễn Vũ Phương ${ }^{2}$, Dương Thu Hồng ${ }^{3}$, Trịnh Minh Phong ${ }^{1}$}

\section{TÓM TẮT}

Mục tiêu: Xác định một số yếu tố có liên quan đến kết quả phuc hồi chức năng bằng phương pháp gương trị liệu kết hợp với vận động trị liệu ở bệnh nhân liệt nửa người do đột quy não. Đối tượng và phương pháp: Nghiên cứu mô tả trên 90 bệnh nhân bị liệt nửa người do đột quy. não được can thiệp bằng

${ }^{1}$ Trường đại học Y Dược Thái Nguyên

²Bệnh viện Trường đại học Y Dược Thái Nguyên

${ }^{2}$ Bệnh viện Y học cổ truyền Cao Bằng

Chịu trách nhiếm chính: Vũ Thị Tâm

Email: bstamphcn@gmail.com

Ngày nhận bài: 23.11.2020

Ngày phản biện khoa học: 30.12.2020

Ngày duyệt bài: 8.01.2021 phương pháp gương trị liệu tại bệnh viện Y học cổ truyền Cao Bằng thời gian từ ngày 3/7/2018 đến ngày 3/7/2020. Kết quả và kết luận: Ớ nhóm tuổi 60 trở xuống có tỷ lệ vận động tốt là $92,31 \%$ cao hơn rất nhiêuu so với nhóm trên 60 tuổi là $20 \%(p<0,05)$. Bệnh nhân có thời gian đến viện sớm dưới 1 tháng hoặc từ 1 đến 3 tháng sau khi đột quy có tỷ lệ vận động tốt lần lượt là $96,43 \%$ và $86,21 \%$ cao hớn nhiêu so với bênh nhân đến muộn sau 3 tháng là 39,39\% $(p<0,05)$. Bệnh nhân có về khiếm khuyết thần kinh theo thang điểm NIHSS ở mức độ nhe thì kết quả phục hồi chức năng đạt mức độ tốt chiểm tỉ lệ $100 \%$ $(p<0,05)$. Các yếu tố giới, bên liẹt, loai tổn thương não không có mối liên quan đến kết quả phục hồi chức năng.

Tư khóa: Đột quỵ não, phục hồi chức năng, vật lý trị liệu, nhồi máu não, vận động trị liệu, gương trị liệu. 